\title{
Caracterização genética de rizóbio isolados de solos no Amazonas baseada na técnica de PCR-RFLP
}

\section{Genetic characterization of rhizobia isolated from Amazonas soils based on the technique of PCR-RFLP}

\author{
Aloísio Freitas Chagas Junior ${ }^{1 *}$; Luiz Antonio de Oliveira ${ }^{2}$; \\ Arlem Nascimento de Oliveira ${ }^{3}$
}

\section{Resumo}

Poucas são as informações referentes à caracterização molecular de rizóbios nativos isolados de solos no Amazonas. Assim, o objetivo deste trabalho foi a caracterização genética de rizóbios isolados de nódulos de caupi usando o método PCR-RFLP dos genes ribossomais 16S rRNA e as enzimas de restrição HinfI, MspI, e MboI. A análise incluiu 20 isolados nativos e dez estirpes-referência de diferentes origens. Os resultados indicaram uma grande variabilidade genética com a formação de oito grupos em um dendrograma com um nível de similaridade variado.

Palavras-chave: Diversidade genética, ecologia microbiana, diversidade microbiana

\begin{abstract}
Few are the details concerning the molecular characterization of native rhizobia isolates from Amazonas soils. The aim of the present study was the genetic characterization of rhizobia isolated from nodules of cowpea using the method PCR-RFLP of the ribosome genes 16S rRNA and the restriction enzymes Hinfl, MspI, and MboI. The analysis included 20 native isolates and ten reference strains from different origins. The results indicated a great genetic variability with the formation of eight groups in one dendrogram with a varied level of similarity.
\end{abstract}

Key words: Genetic diversity, microbial ecology, microbial diversity

1 Professor, Dr. Universidade Federal do Tocantins - Campus Universitário de Gurupi; Cx. Postal: 66, CEP: 77404-970, Gurupi TO.; E-mail: chagasjraf@uft.edu.br

2 Pesquisador, PhD. Instituto Nacional de Pesquisas da Amazônia, Coordenação de Pesquisas em Ciências Agronômicas; CEP: 69060-000, Manaus -AM.; E-mail: luizoli@inpa.gov.br

3 Professor, Dr. Universidade Federal do Amazonas, Dep. de Ciências Biológicas; CEP: 69077-000, Manaus - AM.; E-mail: arllem@yahoo.com.br

* Autor para correspondência 
$\mathrm{O}$ advento dos métodos moleculares baseados nos estudos do genoma bacteriano constituiu-se numa fonte abundante de dados para rizóbio. A taxonomia das bactérias fixadoras de nitrogênio, isoladas em diferentes ecossistemas, em geral tem sofrido uma revisão substancial, devido aos métodos moleculares de análise filogenética (CHEN et al., 2000; GRANGE; HUNGRIA, 2004; McINNES et al., 2004). Os dados levantados nos estudos genéticos de populações dos diferentes gêneros de rizóbio indicam que há um alto grau de diversidade genética deste grupo (SIKORA; REDZEPOVIC, 2003).

Os maiores avanços na utilização de técnicas de biologia molecular estão sendo obtidos pela comparação das seqüências de nucleotídeos do DNA, em especial a região que codifica o $16 \mathrm{~S}$ rRNA, considerado conservado entre as bactérias, mas ao mesmo tempo, suficientemente variável e com uma quantidade de informações capazes de revelar, claramente, as relações filogenéticas entre as espécies (WEISBURG et al., 1991; CHUEIRE et al., 2000). Os estudos de filogenia também se beneficiaram pela técnica de PCR (Polymerase Chain Reaction), que permite a amplificação de seqüências definidas do DNA (CHUEIRE et al., 2000) e que também facilitou as análises da molécula do 16S rRNA de bactérias fixadoras de nitrogênio. Variações e combinações de métodos estão sendo utilizadas para verificar a posição taxonômica das bactérias e, alguns, mostram boa correlação com o seqüenciamento do $16 \mathrm{~S}$ rRNA. Destaca-se, entres esses métodos, a reação de PCR associada à metodologia de RFLP (Restriction Fragment Length Polymorphism), em geral, com amplificações de regiões de genes cromossômicos conservados, como o $16 \mathrm{~S}$ rRNA.

Poucas são as informações referentes à caracterização molecular de rizóbios nativos isolados de solos no Amazonas em função da escassez de estudos dessa natureza na região. Assim, este estudo teve, por objetivo, a caracterização geneticamente de rizóbios isolados de nódulos de feijão caupi obtidos de amostras de solos no Amazonas, por meio da técnica de PCR-RFLP dos genes ribossomais $16 \mathrm{~S}$ rRNA.

Foram utilizados 20 isolados obtidos da Coleção de Rizóbio do Laboratório de Microbiologia do Solo do Instituto Nacional de Pesquisas da Amazônia (INPA). Essas bactérias foram previamente isoladas de solos de terra firme e várzea da região, usando o feijão caupi (Vigna unguiculata L. Walp.) como planta isca (XAVIER etal., 1997). Outras 10 estirpesreferência foram obtidas da Coleção de Cultura da Embrapa Agrobiologia (Seropédica, RJ).

As bactérias foram transferidas para placa de Petri contendo meio YMA (VINCENT, 1970) e incubadas a $28^{\circ} \mathrm{C}$ por aproximadamente cinco dias. A partir de protocolos tradicionais, foram realizadas algumas adaptações que permitiram a otimização dos resultados com os isolados obtidos e as estirpes-referência. As bactérias foram repicadas e cultivadas em meio YM (VINCENT, 1970) sobre um agitador rotatório $(100 \mathrm{rpm})$ a $26+2^{\circ} \mathrm{C}$, por três e cinco dias para rizóbios de crescimento rápido e lento, respectivamente. Posteriormente, foi realizada a extração do DNA genômico e realizada a amplificação do mesmo pela técnica da PCR com os oligonucleotídios fD1 (3' - CCCGGGATCCA AGCTTAAGGAGGTGATCCAGCC - 5' e rD1 (5' - CCGAATTCGTCGACAACAGAGTTTGAT CCTGGCTCAG - 3'), que amplificam praticamente toda a região do DNA (aproximadamente $1500 \mathrm{pb}$ ) que codifica o gene 16S rRNA (CHEN et al., 2000). Cada repetição constituiu em um volume final de $25 \mu \mathrm{L}$, compostos por: $14,2 \mu \mathrm{L}$ de água deionizada estéril; 2,5 $\mu \mathrm{L}$ de dNTPs (1,5 mM de cada); $2,5 \mu \mathrm{L}$ de tampão 10X; 2,5 $\mu \mathrm{L} \mathrm{MgCl2} \mathrm{(50} \mathrm{mM);} \mathrm{1,0} \mu \mathrm{L}$ de cada oligonucleotídio ( 5 pmoles $\mu \mathrm{L}-1) ; 0,3 \mu \mathrm{L}$ de Taq DNA polimerase ( $5 \mathrm{U} / \mu \mathrm{L})$ e $1,0 \mu \mathrm{L}$ de DNA da amostra (10 ng $\mu \mathrm{L}-1)$. A reação foi conduzida em um termociclador "Peltier Thermal Cycler MJ96G" (Biocycler), com um ciclo inicial de desnaturação a 
$95{ }^{\circ} \mathrm{C}$ por 2 min.; a $94{ }^{\circ} \mathrm{C}$ por $15 \mathrm{~s}$; anelamento a $55^{\circ} \mathrm{C}$ por $45 \mathrm{~s} ; 30$ ciclos de desnaturação; e extensão a $72{ }^{\circ} \mathrm{C}$ por 2 min.; um ciclo final de extensão a $72{ }^{\circ} \mathrm{C}$ por 5 min.; os tubos foram mantidos a $4{ }^{\circ} \mathrm{C}$. Os produtos de PCR foram digeridos com as enzimas de restrição HinfI, MspI e MboI (Invitrogen - Life Technologies) reconhecedoras de 4 (MspI e MboI) e 5 (HinfI) pares de bases. Para cada enzima, foi preparada uma mistura contendo: $6 \mu \mathrm{L}$ do produto do PCR; $1 \mu \mathrm{L}$ do tampão específico para cada enzima (10X); 1,0 $\mu \mathrm{L}$ da enzima (5 U/reação); 2,0 $\mu \mathrm{L}$ de água deionizada estéril; incubado por duas horas a $37^{\circ} \mathrm{C}$.

Os fragmentos obtidos foram analisados em eletroforese com gel de agarose $(2,5 \%)$ corados com brometo de etídio, em tampão TBE 1,0X (5,4 $\mathrm{g}$ de Tris-base, 2,75 $\mathrm{g}$ de ácido bórico, $2 \mathrm{~mL}$ de EDTA 0,5 M pH 8,0, para um litro de solução), a $100 \mathrm{~V}$ por 4 horas. As bandas foram visualizadas e fotografados sob radiação UV. Foi utilizado um marcador molecular (100 bp ladder - Fermentas), para estimar o tamanho dos fragmentos de DNA.

Foi realizado um mapeamento dos sítios de restrição para cada enzima, com intuito de individualizá-los (AMORIM, 1997) e permitir a construção de uma matriz geral dos estados de caracteres (presença/ausência de sítios de restrição). Os resultados foram analisados com auxílio do programa MVSP (Multi-Variate Statistical Package versão 3.13) e o método de agrupamento de médias aritméticas (UPGMA). Nessa análise, utilizou-se o coeficiente de similaridade de Jaccard.

Tem sido relatado, freqüentemente, que, embora sejam constatadas elevadas variabilidades morfológica, fisiológica e genética entre estirpes de rizóbio, a região do gene $16 \mathrm{~S}$ rRNA não reflete essa diversidade. Neste estudo, a amplificação com os oligonucleotídios fD1 e rD1 produziu, em todos os isolados, um único fragmento, com aproximadamente $1.500 \mathrm{pb}$. Quando esse fragmento foi digerido com três enzimas de restrição (Figura 1) e os fragmentos analisados em conjunto, constatou- se grande variabilidade genética (Figura 2) e a formação de 8 grupos com um nível de similaridade superior a 50\%. Dois isolados (INPA R817 e INPA R808) e quatro estirpes-referência (BR 524, BR 10026, BR 10016 e BR 112) se agruparam com os demais grupos, porém, com níveis de similaridades inferiores a $50 \%$ (Figura 2).

Os grupos um (G1), três (G3), cinco (G5), seis (G6) e sete (G7) foram formados apenas por isolados nativos de rizóbio, não ocorrendo à presença de estirpes-referência (Figura 2). O grupo 1 foi formado pelos isolados INPA R814a e INPA R811; o grupo três pelos isolados INPA R851 e INPA R813; o grupo cinco com os isolados INPA R949, INPA R927 e INPA R918; o grupo seis pelos isolados INPA R993, INPA R1003, INPA R822, INPA R921, INPA R901 e INPA R814b; o grupo sete pelos isolados INPA R820 e INPA R815. O grupo dois (G2) foi formado pelas estirpesreferência BR 10052 (Rhizobium leguminosarum bv. phaseoli) e BR 523 (Mesorhizobium tianshanense), enquanto o quatro (G4) incluiu as estirpes BR 525 (Sinorhizobium medicae) e BR 522 (Mesorhizobium mediterraneum). Já o grupo 8 (G8) foi formado pelos isolados INPA R999, INPA R874 e INPA R980 e pelas estirpes-referência BR 115 (Bradyrhizobium elkanii) e BR 114 (Bradyrhizobium japonicum). Nesse grupo foram observadas similaridades de 93\% e 66\% entre as estirpes-referência BR 115 e BR 114 e os isolados, respectivamente (Figura 2).

Considerando-se que existem seis gêneros de rizóbio (Allorhizobium, Azorhizobium, Bradyrhizobium, Rhizobium, Mesorhizobium e Sinorhizobium), e que vários grupos genéticos não se agruparam com as estirpes-referência, há uma grande possibilidade da existência de novas espécies e/ou estirpes no grupo de isolados nativos estudados. Resultados semelhantes foram documentados por vários autores (CHEN et al., 2000; SIKORA; REDZEPOVIC, 2003; ZILLI et al., 2004), segundo os quais, rizóbios isolados de diferentes regiões apresentam elevada diversidade 
fenotípica e genética e podem também representar novas espécies.

O dendrograma derivado dos perfis de PCRRFLP mostrou que os isolados nativos agrupados com a estirpe-referência BR 115, com nível de similaridade maior que $80 \%$, podem ser do gênero Bradyrhizobium.

Chueire et al. (2000) também observaram similaridade entre estirpes de Bradyrhizobium determinando a posição taxonômica das estirpes recomendadas para as culturas da soja e feijão, pela técnica de PCR-RFLP da região $16 \mathrm{~S}$ rRNA. Assim como, Kwon et al. (2005) por meio da análise filogenética dos gêneros de Bradyrhizobium, Mesorhizobium, Rhizobium e Sinorhizobium.

Embora a maioria dos isolados agrupados com as estirpes-referência, de acordo com as características genéticas (PCR-RFLP), tenha sido relacionada com os gêneros Bradyrhizobium e Rhizobium, dois isolados (INPA R814a e INPA R811) formaram grupos separados ou com baixa similaridade com estirpes-referência. Esses resultados indicam que estes grupos divergentes podem pertencer a outros gêneros ou espécies. Porém, para confirmar essa inferência e esclarecer a posição taxonômica desses isolados, tornam-se necessários estudos genéticos mais aprofundados como o seqüenciamento da região $16 \mathrm{~S}$ rRNA.
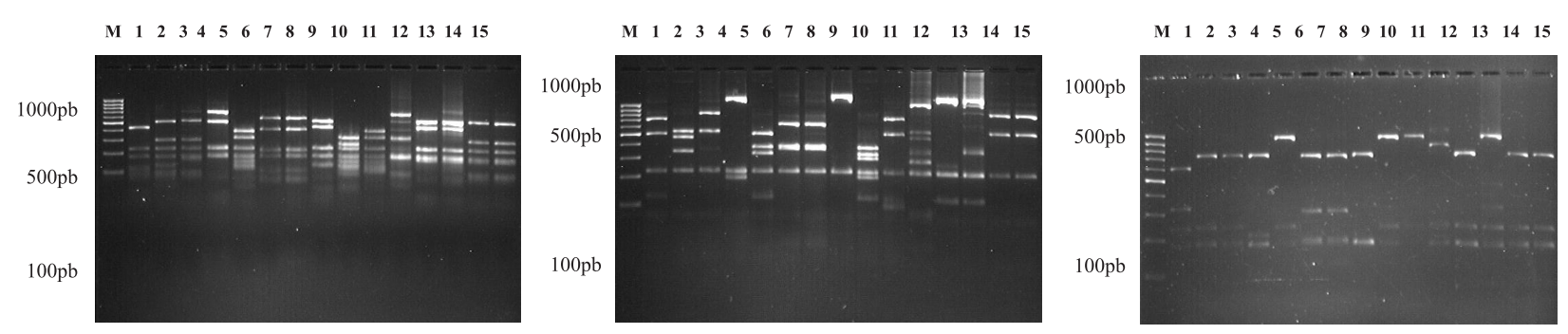

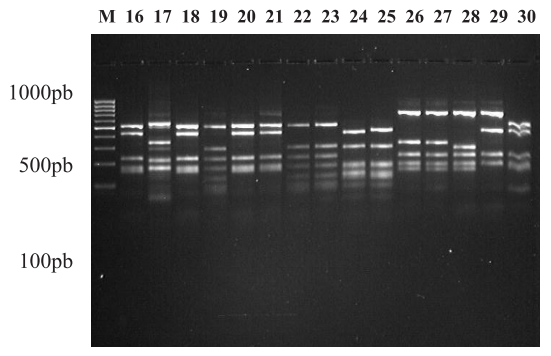

MspI

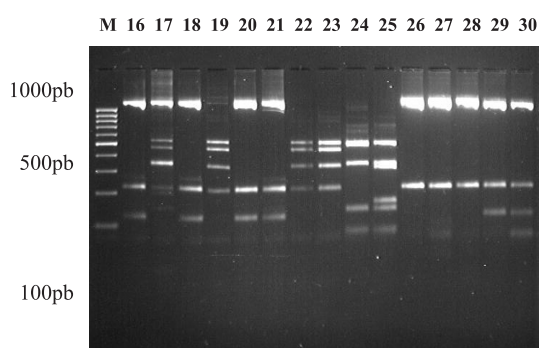

HinfI

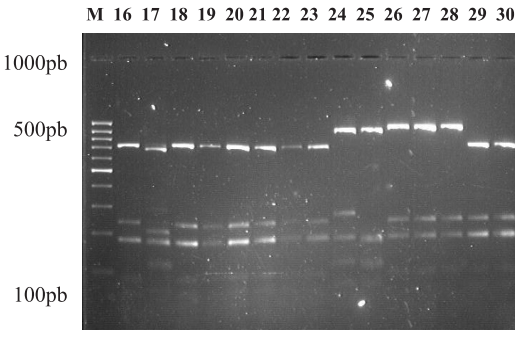

MboI

Figura 1. Fragmentos obtidos por PCR-RFLP da região correspondente ao 16S rRNA utilizando as enzimas de restrição MspI, HinfI e MboI, em gel de agarose a 2,5\%, dos isolados e estirpes-referência.

(M) marcador de 100 pares de base; (1) BR 112; (2) BR 115; (3) BR 114, (4) BR 10016; (5) BR 525; (6) BR 523; (7) BR 10052; (8) BR 10016; (9) BR 524; (10) BR 522; (11) INPA R808; (12) INPA R815; (13) INPA R820; (14) INPA R811; (15) INPA R814a; (16) INPA R814b; (17) INPA R817; (18) INPA R822; (19) INPA R874; (20) INPA R901; (21) INPA R921; (22) INPA R980; (23) INPA R999; (24) INPA R813; (25) INPA R851; (26) INPA R918; (27) INPA R927; (28) INPA R949; (29) INPA R1003; (30) INPA R993. 


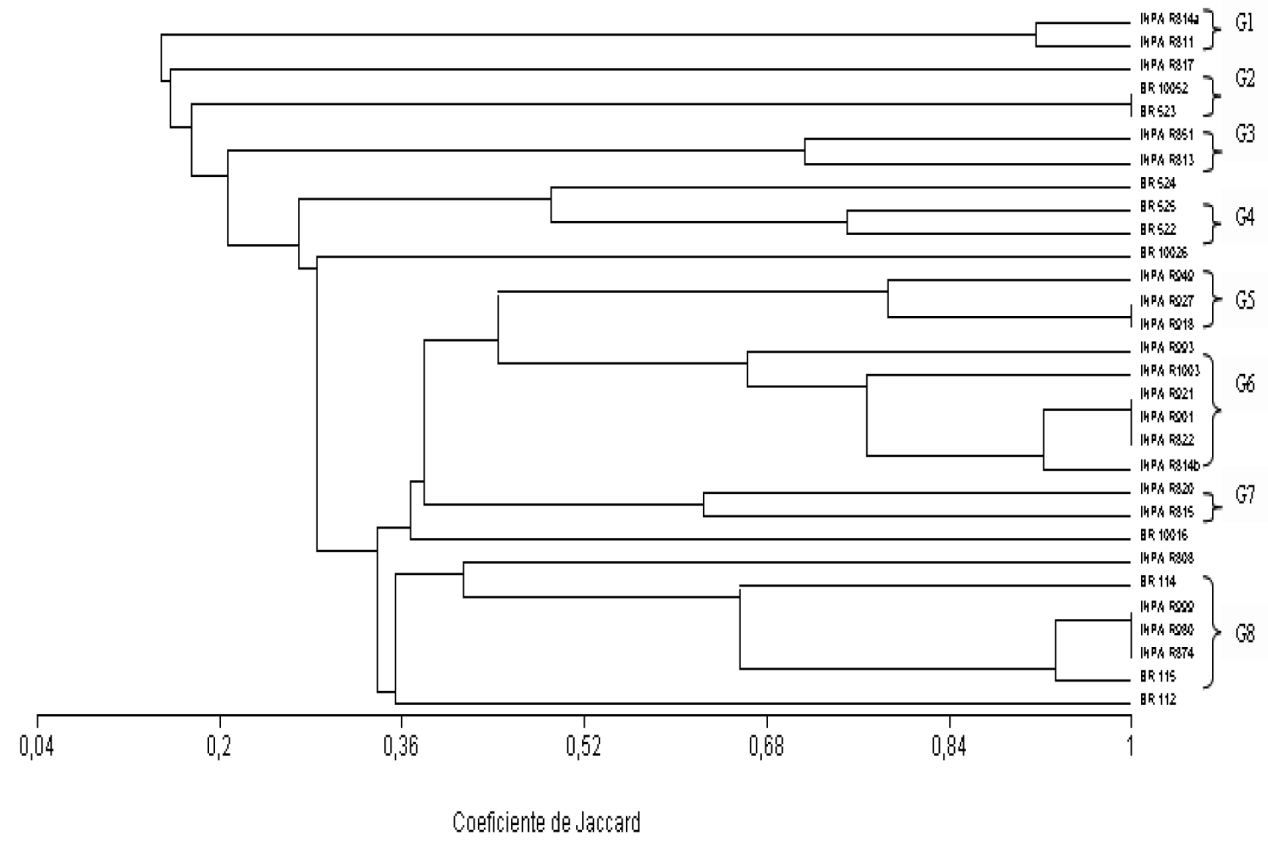

Figura 2. Dendrograma de isolados nativos da Amazônia e estirpes-referência de rizóbio obtido com os fragmentos resultantes da análise por RFLP - PCR da região ribossomal do gene 16S rRNA com três enzimas de restrição (MSP I., HINF I e MBO I). Análise usando o algoritmo UPGMA com o coeficiente de Jaccard.

\section{Agradecimentos}

À UFAM e INPA pelo espaço físico e à CAPES, FAPEAM e CNPq pelos recursos financeiros que viabilizaram essa pesquisa.

\section{Referências}

AMORIM, D. S. Elementos básicos de sistemática filogenética. 2. ed. Ribeirão Preto: Holos, 1997. 276 p.

CHEN, L. S.; FIGUEREDO, A.; PEDROSA, F. O.; HUNGRIA, M. Genetic characterization of soybean rhizobia in Paraguay. Applied and Environmental Microbiology, Washington, v. 66, n. 11, p. 5099-5103, 2000.

CHUEIRE, L. M. O.; BANGEL, E.; FERREIRA, C.; GRANGE, L.; CAMPO, R. J.; MOSTASSO, F. L.; ANDRADE, D. S.; PEDROSA, F. O.; HUNGRIA, M. Classificação taxonômica, baseada na caracterização molecular, das estirpes de rizóbio recomendadas para as culturas da soja e do feijoeiro. Londrina: Embrapa - Soja, 2000. 32 p. (Boletim de Pesquisa, n. 3).
GRANGE, L.; HUNGRIA, M. Genetic diversity of indigenous common bean (Phaseolus vulgaris) rhizobia in two Brazilian ecosystems. Soil Biology and Biochemistry, Oxford, v. 36, n. 9, p. 1389-1398, 2004.

KWON, S. W.; PARK, J. Y.; KIM, J. S.; KANG, J. W.; CHO, Y. H.; LIM, C. K.; PARKER, M. A.; LEE, G. B. Phylogenetic analysis of the genera Bradyrhizobium, Mesorhizobium, Rhizobium and Sinorhizobium on the basis of $16 \mathrm{~S}$ rRNA gene and internally transcribed spacer region sequences. Journal of Systematic and Evolutionary Microbiology, Reading, v. 55, p. 263-270, 2005.

McINNES, A.; THIES, J. E.; ABBOTT, L. K.; HOWIESON, J. G. Structure and diversity among rhizobial strains, populations and communities - a review. Soil Biology and Biochemistry, Oxford, v. 53, p. 1118-1121, 2004.

SIKORA, S.; REDZEPOVIC, S. Genotypic characterisation of indigenous soybean rhizobia by PCRRFLP of 16S rDNA, rep-PCR and RAPD analysis. Food Technology and Biotechnology, Zagreb, v. 41, n. 1, p. 61-67, 2003. 
VINCENT, J. M. A manual for practical study of root nodule bacteria. Oxford: Blackwell Scientific Publication, 1970. 140 p. (IBP Handbook, n. 15)

WEISBURG, W. G.; BARNS, S. M.; PELlETIER, D. A.; LANE, D. J. 16S ribosomal DNA amplification for phylogenetic study. Journal of Bacteriology, Washington, v. 173, n. 2, p. 697-703, 1991.
XAVIER, G. R.; MARTINS, L. M. V.; ZILLI, J. E.; PEIXOTO, R. C.; RUMJANEK, N. G. Protocolo operacional cultivo de planta-isca para isolamento de rizóbio a partir de nódulo de planta-isca. Seropédica: Embrapa - Agrobiologia, 1997. 7 p. (Documentos, n. 43).

ZILLI, J. E.; VAIISHESKI, R. R.; FREIRE FILHO, F. R.; NEVES, M. C. P.; RUMJANEK, N. G. Assessment of cowpea rhizobium diversity in cerrado areas of northeastern Brazil. Brazilian Journal of Microbiology, Rio de Janeiro, v. 35, n. 4, p. 281-287, 2004. 